\title{
REMOVING BIOLOGICAL TRENDS FROM TREE-RING SERIES: TESTING MODIFIED HUGERSHOFF CURVES
}

\author{
KEYAN FANG ${ }^{1,2 *}$, XIAOHUA GOU ${ }^{1}$, KENNETH PETERS ${ }^{2}$, JINBAO LI $^{2}$, and FEN ZHANG ${ }^{1}$ \\ ${ }^{1}$ MOE Key Laboratory of Western China’s Environmental Systems, Lanzhou University, Lanzhou 730000, China \\ ${ }^{2}$ Tree-Ring Lab, Lamont-Doherty Earth Observatory of Columbia University, New York, NY 10964, USA
}

\begin{abstract}
The performance of the Hugershoff curve on fitting the growth trends of tree-ring series was tested using ring-width series with different starting years. The fitted values tend to be biased by treering series close to pith, a phenomenon that was referred to as the "start-fitting problem". We determined three parameters with specific biological age-related meanings for the Hugershoff growth curve, i.e. the maximum growth, the maximum slope and the maximum changing ratio of slopes. A set of modified Hugershoff curves with different starting years was proposed to mitigate the start-fitting problem. Behavior of the modified Hugershoff curves on tree-ring series standardizations was tested and discussed. The "end-fitting problem" suggests that deviations in one interval could bias the fitted values of other time periods by using the Hugershoff curve.
\end{abstract}

Keywords: tree-ring, standardization process, Hugershoff curve, biological trends.

\section{INTRODUCTION}

Methods of removing the biological trends (referred to as the biological age-related trend in this paper) in tree-ring measurements fall into three major types: deterministic curves, stochastic curves, and empirical curves (Cook and Kairiukstis 1990; Helama et al. 2004). Stochastic functions, such as the smoothing spline and the Friedman smoother, are employed to model biological trends in tree-ring series in a flexible way (Fritts 1976; Cook and Peters 1981; Friedman 1984). These stochastic curves may at the same time remove much of the climate signal, because they do not have biological meaning (Cook and Kairiukstis 1990). These functions are more applicable for trees that experienced strong disturbance, such as trees in forest interiors (Cook and Peters 1981; Cook and Kairiukstis 1990). Regional curve standardization (RCS), an empirical curve, is theorized to represent only the biological trend dependent on availability of sufficiently large samples with homogeneous biological trends and exactly dated ages (Briffa 1992, 1995; Esper et al. 2002, 2003; Cook et al. 2004). The biological trends

\footnotetext{
*Corresponding author: kf2278@columbia.edu
}

of individual tree-ring series in open-canopy forests can often be fitted by deterministic curves, such as a linear function, negative exponential curve and Hugershoff curve (Fritts 1976; Bräker 1981; Cook and Kairiukstis 1990).

The monotonic curves of the linear function or the negative exponential function cannot imitate the accelerated growth of tree rings close to the pith. Such tree rings could be fitted by using the Hugershoff curve (Warren 1980, 1981; Bräker 1981), namely

$$
f(t)=a t^{b} e^{(-c t)}+d
$$

where $t$ denotes age, $f(t)$ denotes the ring-width value for $t$, the superscript $b$ denotes the power, $c$ indicates the exponential argument, and $d$ is the intercept. If $b$ equals 0 , the function (1) equals the offset exponential curve. Likewise, the Hugershoff curve becomes a linear function when $b$ and $c$ equal 1 and 0 , respectively. The Hugershoff curve is more representative than the other two deterministic curves. In addition, one could not evaluate the behavior of curve-fits by using parameters calculated from derivatives of the monotonic functions, because the specified pa- 
rameters for monotonic curve are not available (Yang 2002). Therefore we herein select the Hugershoff curve to test the performance of deterministic curves on standardizing tree-ring series. The goals of this study are to (1) calculate the parameters with biological meaning for the Hugershoff curve, (2) evaluate the performance of the Hugershoff curve on standardizing tree-ring series, and (3) test a set of modified Hugershoff curves based on these parameters and evaluate their performance in removing the biological trends of tree-ring series.

\section{PARAMETERS OF THE HUGERSHOFF CURVE}

We propose three parameters that determine the shape of the Hugershoff curve, i.e. the maximum growth (MG), the maximum slope (MS), and the maximum changing ratio of slopes (MRS), to evaluate the performance of curve-fit (Figure 1). With regards to biological meanings, MG indicates the year of maximum growth at the peak of the fitted curve. The MS denotes the year the growth curve is at its steepest rising or declining trends, which may be the years when trees experience the strongest biological influences. The MRS denotes the year when the slope of the curve changes most, i.e. the turning point from a strongly declining trend to a relatively flat trend for tree-ring series. The MRS may be the turning point for tree rings from strong biological influences to weak biological influences (Figure 1). It is expected that a common growth pattern between trees would lead to similar values of the three parameters. These parameters are estimated by calculating the derivatives of the Hugershoff function.

The MG is the point where the slope of the Hugershoff curve equals zero. The slope of the curve is calculated by the first order derivative, namely

$$
f^{\prime}(t)=a b t^{(b-1)} e^{(-c t)}-a c t^{b} e^{(-c t)},
$$

where $f^{\prime}(t)$ denotes the first derivative of the curve. For $f^{\prime}(t)=0$, the year $t$ for the MG is calculated as $t=b / c$. The year of MG lower than zero

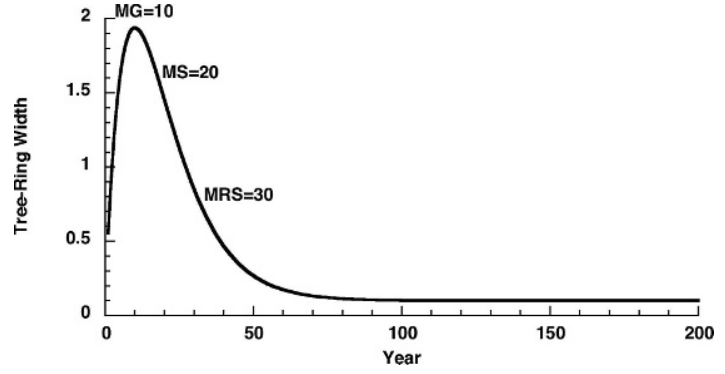

Figure 1. Plot of a Hugershoff curve with parameters of $a, b, c$ and $\mathrm{d}$ equal $0.5,1,0.1$ and 0.1 , respectively, according to function (1), and its associated values of $\mathrm{MG}$ (maximum growth), MS (maximum slope), and MRS (maximum changing ratio of slopes) at 10, 20 and 30 years, respectively.

indicates that the maximum growth occurs prior to the starting year of tree-ring series.

The MS is the year when the changing ratio of the curve slopes equals zero. The changing ratios of the slopes of the Hugershoff curve is calculated as

$$
\begin{aligned}
f^{\prime \prime}(t)= & a b(b-1) t^{(b-2)} e^{(-c t)}-2 a b c t^{(b-1)} e^{(-c t)} \\
& +a c^{2} t^{b} e^{(-c t)}
\end{aligned}
$$

where $f^{\prime \prime}(t)$ is the second derivative of the curve. Let $f^{\prime \prime}(t)=0$, for $b>0, t_{1}=\frac{b+\sqrt{b}}{c}, t_{2}=\frac{b-\sqrt{b}}{c}$; when $b<0, t_{1}=\frac{\sqrt{b^{2}-b}}{c} e^{\tan ^{-1} \frac{-1}{\sqrt{-b}}}, t_{2}=\frac{\sqrt{b^{2}-b}}{c}$ $e^{\tan ^{-1} \frac{1}{\sqrt{b}}}$, where $t_{1}$ and $t_{2}$ are solutions of the equation. The solutions of $t$ that are lower than zero indicate placement of the years of MS before the starting year. In this paper we only use the larger $t$ solution for the following analyses, e.g. when $b>1$ we select the solution at the year of $t_{1}=\frac{b+\sqrt{b}}{c}$.

Likewise, the changing ratio of slopes is given by the third-order derivative of the function, that is

$$
\begin{aligned}
f^{\prime \prime \prime}(t)= & a b(b-1)(b-2) t^{(b-3)} e^{(-c t)} \\
& -3 a b(b-1) c t^{(b-2)} e^{(-c t)} \\
& +3 a b c^{2} t^{(b-1)} \mathrm{e}^{(-c t)} \\
& -a c^{3} t^{b} \mathrm{e}^{(-c t)}
\end{aligned}
$$

where $f^{\prime \prime \prime}(t)$ denotes the third-order derivative of 
the Hugershoff curve. In this paper we are only interested in real solutions. The MRS is expected to exist after the MG and MS. That is, the year of MRS should be greater than the MG and MS. The years of MRS are the real solutions greater than zero because the equation (4) equals 0 .

For $b \leq 0, \mathrm{t} \leq b / c$ (no useful solution), for 0 $<b \leq 1, t=\frac{b}{c}+\frac{\sqrt[3]{b}(\sqrt[3]{1+\sqrt{1-b}}+\sqrt[3]{1-\sqrt{1-b}})}{c}$ (one useful solution). For $b>1, t_{1}=$ $\frac{b}{c}+\frac{2 \sqrt{b} \cos \theta}{c}, \quad t_{2}=\frac{b}{c}+\frac{2 \sqrt{b} \cos \left(\theta+120^{\circ}\right)}{c}, t_{3}=$ $\frac{b}{c}+\frac{2 \sqrt{b} \cos \left(\theta+240^{\circ}\right)}{c}$, where $\theta=\frac{1}{3} \tan ^{-1} \sqrt{b-1}$. The largest root was selected as the useful solution for this study.

For those old growth tree ring-width series showing the Hugershoff growth pattern, these parameters may be applicable in dendroecological studies. For example, for a species in a site with common biological growth pattern, similar values of these parameters between series may be seen. On the other hand, changes of these parameters might correspond to the gradients between species or sites. These linkages could be important indicators of interactions between climate change and tree growth. Based on the climate-growth relationships, one could evaluate impacts of future climate change on forests and the feedbacks of forest systems. In this study, we focus on the application of these parameters in standardization of tree rings.

\section{PROBLEMS OF THE HUGERSHOFF CURVE-FIT}

\section{Start-Fitting Problem}

We selected a tree ring-width series coded as Dulan29b collected by Sheppard et al. (2004) to test the skill of curve-fitting using the Hugershoff curve. The selected series that shows a clear Hugershoff growth pattern is taken from a long-lived tree of Sabina przewalskii at an open canopy forest in the cold and arid Qinghai province, China (Sheppard et al. 2004). This tree-ring series is well fitted by the Hugershoff curve, with the parameters of MG, MS and MRS at the years 1352, 1416 and 1477 (Figure 2 and Table 1). In order to imitate the sampling process that may lose many starting rings

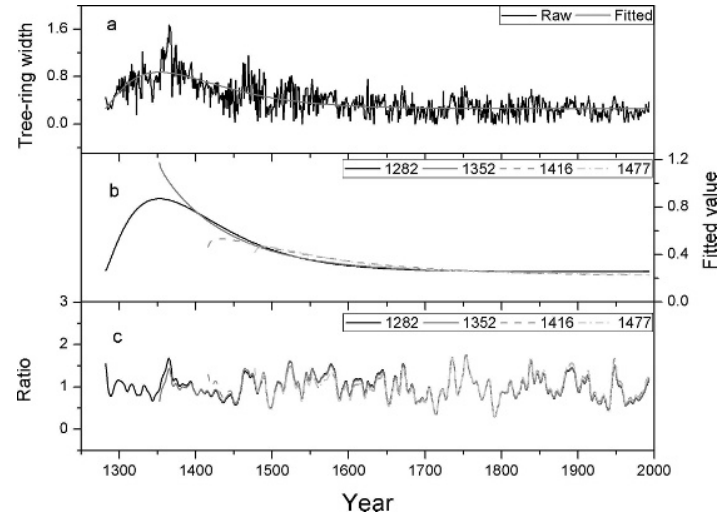

Figure 2. Plot showing (a) tree-ring measurements (Dulan29b) and the Hugershoff curve fitted values, as well as comparisons of (b) fitted Hugershoff curves and (c) ratios for the original and modified tree-ring series with differing starting years.

close to the pith, we deleted some innermost rings of the series to compose new tree-ring series starting from the years at 1352, 1416 and 1477, which equal the MG, MS and MRS calculated from the original series as seen in Table 1. In order to avoid the bias caused by high variance at the early portion of the chronology, the so-called "heteroscedasticity problem" (Cook and Peters 1997), we herein calculated the tree-ring indices as ratios between raw and fitted values.

Because the newly composed series with modified starting years are derived from the same tree-ring sample, they are expected to retain the same biological signal and are hypothetically expected to be fitted by the same biological curve. However, as shown in Figure 2, different fitted curves are found, particularly at the earlier portions. For example, the peaks of the fitted curves are different, indicating different values of the MG (Figure 2 and Table 1). This is seen in the clearly different peaks of the fitted curves (Figure 2). The change of fitted values results in modified ratios between these series with different starting years, particularly at the early portions (Figure 2). Increased degrees of freedom and better curve-fit led to increased $F$ values (Table 1). As indicated by Table 1, it appears that MG, MS and MRS parameters are more sensitive to the innermost ring-width data. This may be because MG, MS and MRS for the fitted curve of tree rings are concentrated at the beginning portions, 
Table 1. Parameters and statistics of the Hugershoff curve fitting for raw and the modified tree-ring series (Dulan 29b) with different starting years. Parameters below are identical to those in Figure 1, and F indicates the F-test statistic.

\begin{tabular}{cccccrrrrr}
\hline Time-Span & $\mathrm{a}$ & $\mathrm{b}$ & $\mathrm{c}$ & $\mathrm{d}$ & $\mathrm{F}$ & $\mathrm{MG}$ & $\mathrm{MS}$ & MRS \\
\hline $1282-1993$ & 0.012 & 1.264 & 0.018 & 0.256 & 1068 & 1352 & 1416 & 1477 \\
$1352-1993$ & 0.936 & -0.024 & 0.010 & 0.249 & 940 & 1349 & 1417 & $*$ \\
$1416-1993$ & 0.249 & 0.125 & 0.007 & 0.217 & 595 & 1432 & 1482 & 1548 \\
$1477-1993$ & 0.189 & 0.134 & 0.009 & 0.229 & 491 & 1490 & 1529 & 1580 \\
\hline
\end{tabular}

* Note that for this mono-decreasing fitted curve no meaningful root was available

where the biological signals are stronger. It appears that the fitted Hugershoff curve tends to be biased by the innermost tree rings (Figure 2). We coined this problem the "start-fitting problem" in this paper.

\section{End-Fitting Problem}

The noise occurring in intervals other than the early periods could bias the globally fitted Hugershoff curve as well. In order to simulate samples such as those from a dead tree, we deleted the 53 outermost rings to compose a new series spanning from 1282-1940. Additionally, the ringwidth values of the 53 outermost rings were systematically doubled to model the short-term growth release from disturbances, e.g. deforestation in recent decades. Because the modifications were only made for outermost tree rings that are derived from the same series, the innermost tree rings are expected to be fitted by the same curves. However, the fitted curves and the associated ratios between raw and fitted data for the innermost rings are slightly different for the period prior to the 53 modified outside ring widths (Figure 3). Accordingly, the values of the MG, MS and MRS are slightly changed (Table 2). These results suggest that the length and the noise of tree-ring series would distort the globally fitted curves. The values of the MG appear to be relatively less variable as shown in Table 2. The MS and MRS shift to early years compared to the original series (Table 2). The rising trend towards present 'lifts' the end of the fitted curves, resulting in a backward shift of the MS and MRS on the fitted curve.

We herein refer to this Hugershoff curve-fit problem as the "end-fitting problem", which is caused by the short disturbances occurring at periods other than the beginning of the series. This "end-fitting problem" for Hugershoff curve-fit described here is related to the "end-effect problem" discussed by Melvin (2004) and segment length curse (Cook et al. 1995; Melvin and Briffa 2008). Unlike the "end-effect problem" proposed by Cook and Peters (1997) that was focused on a bias by calculating ratio from linear curve-fits, other studies (Melvin 2004; Melvin and Briffa 2008) suggested that the fitted curves could be biased by short-term disturbances caused by, for example, "a rotation" of the linear fitted curves. Cook et al. (1995) highlighted a "segment length curse", which suggests that segment length limits the frequency band that can be recovered from standardization. Melvin and Briffa (2008) pointed out that the changed segment length could also lead to changes in the fitted curve. Our study indicates that disturbances for a certain period, such as changed segment length and/or modified

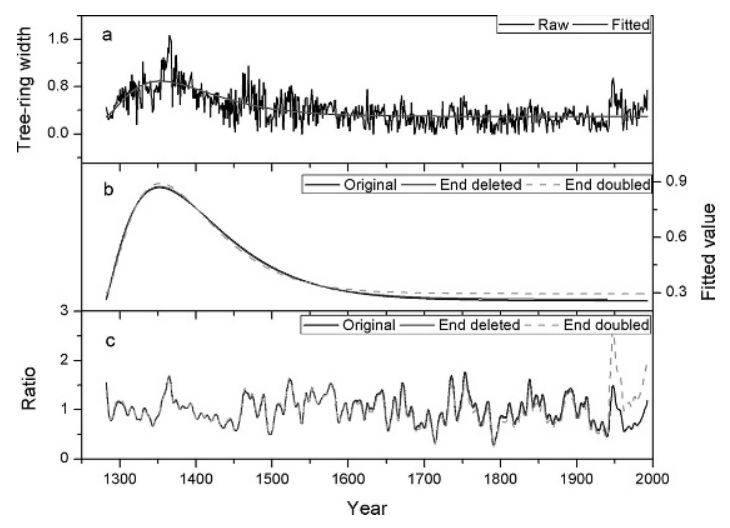

Figure 3. Plot of (a) raw (Dulan29b) and Hugershoff curve fitted tree-ring values, as well as comparisons of (b) fitted Hugershoff curves and (c) ratios for the original and tree-ring series with modified values at the end of the series. 
Table 2. Comparisons of parameters and statistics of the fitted Hugershoff curves for the raw and modified tree-ring series with changed values for recent decades. Parameters are indicated in Figure 1, and F designates the F-test statistic.

\begin{tabular}{lccccrrrr}
\hline Time-span & $\mathrm{a}$ & $\mathrm{b}$ & $\mathrm{c}$ & $\mathrm{d}$ & $\mathrm{F}$ & $\mathrm{MG}$ & $\mathrm{MS}$ & MRS \\
\hline $1282-1993$ & 0.009 & 1.264 & 0.018 & 0.256 & 1068 & 1352 & 1416 & 1477 \\
$1282-1940$ & 0.007 & 1.354 & 0.019 & 0.264 & 998 & 1352 & 1414 & 1472 \\
$1282-1993^{*}$ & 0.003 & 1.663 & 0.023 & 0.294 & 994 & 1353 & 1409 & 1458 \\
\hline
\end{tabular}

* Note that within the full time-span the ring-widths for 1941-1993 are doubled.

values by disturbances, could change the global fitted Hugershoff curve.

The difference between the start-fitting and end-fitting problem is that the former emphasizes that the fitted Hugershoff curve may be biased by short disturbances at the beginning caused by its specific curve pattern. For example, a short-term rising trend occurring at the start of series tends to be fitted according to a start-fitting problem; such a short-term disturbance occurring at other periods could be preserved but may bias the global fitted curve because of an end-fitting problem. Additionally, disturbances occurring at the early periods could also slightly bias the global fitted curve. In this sense, we state with regard to the use of Hugershoff curve that the start-fitting problem is more influential when compared with
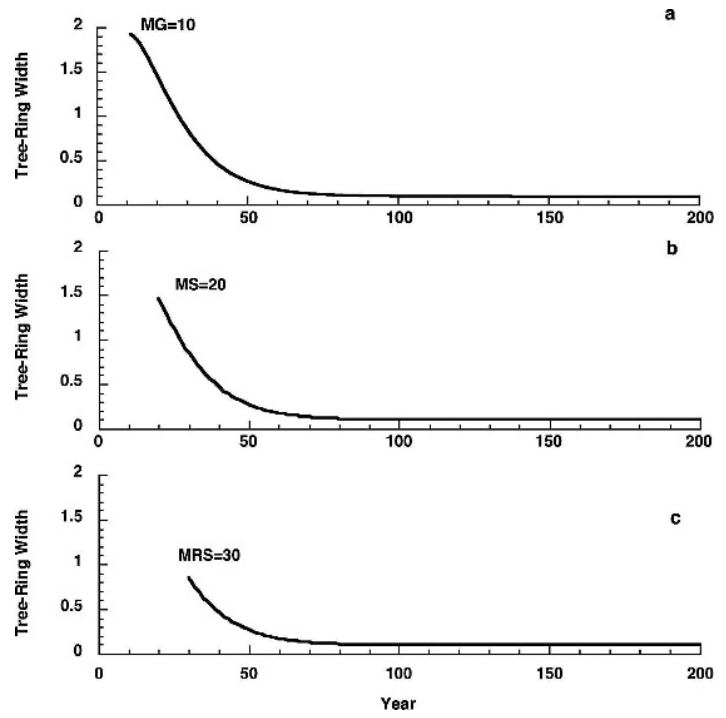

Figure 4. Three versions of modified Hugershoff curve that start from MG, MS and MRS. Parameters in this figure are the same as in Figure 1. the end-fitting problem. We will focus on the startfitting problem for the Hugershoff curve-fit in this study. A generally accepted view is that a deterministic curve such as the Hugershoff curve can better fit the raw data with similar shapes (Fritts 1976). Therefore in the following section we modify the original Hugershoff curve to compose a set of new curves to fit the raw data with different growth patterns (Figure 4).

\section{TESTING THE USE OF MODIFIED HUGERSHOFF CURVES}

\section{A Set of Modified Hugershoff Curves}

We composed a set of modified Hugershoff curves to fit the tree-ring series starting around the years of the MG, MS and MRS (Figure 4). Based on (1), the three modified functions with starting years at MG, MS and MRS are defined as follows:

$f_{1}(t)=a\left(t+\frac{b}{c}-1\right)^{b} e^{-c\left(t+\frac{b}{c}-1\right)}+d$

$f_{2}(t)=a\left(t+\frac{b}{c}+\frac{\sqrt{b}}{c}-1\right)^{b} e^{-c\left(t+\frac{b}{c}+\frac{\sqrt{b}}{c}-1\right)}+d$

$f_{3}(t)=a\left(t+\frac{b}{c}+\frac{R}{c}-1\right)^{b} e^{-c\left(t+\frac{b}{c}+\frac{R}{c}-1\right)}+d$

where $\quad R \quad$ represents $\quad b+\sqrt[3]{b}(\sqrt[3]{1+\sqrt{1-b}}+$ $\sqrt[3]{1-\sqrt{1-b}})$ or $b+2 \sqrt{b} \cos \frac{\theta}{3}$ in (7). In practice, one may determine the use of the modified functions via the similarity between tree rings and the shapes of the functions (Figure 4). Those tree-ring series showing a peak and then steep downward trend are suggested to a selection 
function (5). The function (6) is supposed to be a good fit for the series with a steep downward trend at the beginning. For series that show a relatively flat growth pattern, we recommend the use of (7). We will test the use of these modified Hugershoff curves by fitting the tree-ring series with the "startfitting problem".

\section{Test of the Use of Modified Hugershoff Functions}

The premise for the comparison is that the well fitted curves for tree rings with different starting years should show similar growth patterns with the fitted Hugershoff curve for the unmodified series that shows a Hugershoff growth pattern, i.e. a target curve here. Compared to the Hugershoff curve-fits for tree-ring series with varying starting years (Figure 2), curve-fits using modified Hugershoff functions show shapes closer to the Hugershoff fitted unmodified series, suggesting an improved accuracy of curve-fits (Figure 5). For example, the fitted peaks for those modified series that start after the maximum growth, as shown in Figure 2, are not observed for the fitted curves using the modified Hugershoff curves (Figure 5). Accordingly, the ratios at the early years calculated based on these modified Hugershoff curve-fits follow better the ratios of the Hugershoff curve-fit of the unmodified series (Figure 5). In addition, as suggested by the differences between statistics of these fitted curves for Hugershoff and modified Hugershoff curvefits (Table 1 and Table 3), the statistics (MG, MS and MRS) for the modified Hugershoff are relatively less variable, suggesting a goodness-offit in the early portions when using the modified Hugershoff curves in this respect. To sum up, the modified Hugershoff curves appears to be skillful

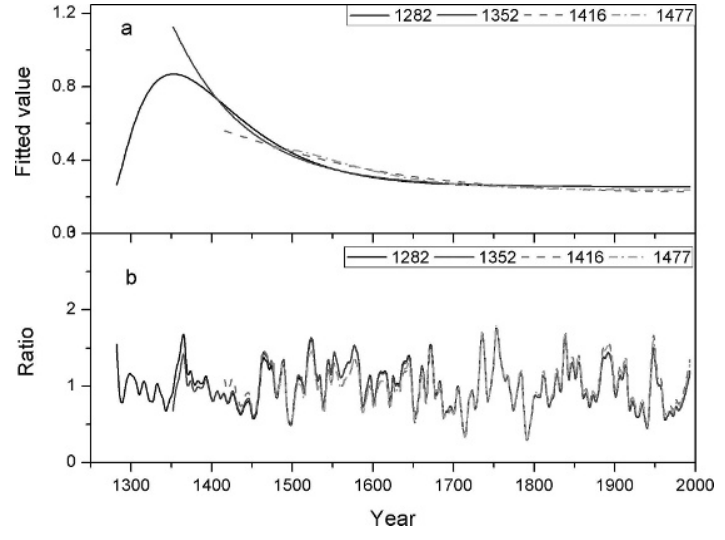

Figure 5. The (a) fitted curves and (b) ratios using modified Hugershoff curves for the tree-ring series (Dulan29b) with different starting years. The fitted curve for the unmodified treering series using Hugershoff curve (black) is also shown for comparison.

at alleviating the "start-fitting problem" for the innermost tree rings.

We further tested the use of modified Hugershoff curve-fit over a population of tree-ring series with a roughly Hugershoff-shape growth curve (Dulan25b, Dulan26a, Dulan29a, Dulan44b, Dulan44c, Dulan50a, Dulan61a, Dulan67b, Dulan68a, Dulan76b), which were extracted from the same sampling site by Sheppard et al. (2004) without including the sample (Dulan29b) used above. The innermost 100 rings were deleted to generate a new population of tree rings with varying starting years. We compared the performances of curve-fits by using the unmodified and modified Hugershoff curves for raw and enddeleted tree rings. The fitted curves were largely fit by function (6) that shows similar shapes to tree rings with the innermost 100 year deleted, which were averaged together with the same starting year. As shown in Figure 6a, there is no clear

Table 3. Parameters and statistics of the fitted modified Hugershoff curves for the tree-ring series with different starting years. Parameters in this table are the same to those in Figure 1, and F is the F-test statistic.

\begin{tabular}{llccccccc}
\hline Time-span & \multicolumn{1}{c}{$\mathrm{a}$} & $\mathrm{b}$ & $\mathrm{c}$ & $\mathrm{d}$ & $\mathrm{F}$ & $\mathrm{MG}$ & $\mathrm{MS}$ & MRS \\
\hline $1352-1993$ & 0.878 & 0.001 & 0.011 & 0.253 & 939 & 1352 & 1355 & 1365 \\
$1416-1993^{*}$ & $6.8 \mathrm{E}-06$ & 2.514 & 0.011 & 0.220 & 595 & 1267 & 1416 & 1588 \\
$1477-1993$ & 0.009 & 1.021 & 0.015 & 0.235 & 494 & 1274 & 1342 & 1477 \\
\hline
\end{tabular}

* Note that it has failed to fit the raw tree-ring series. 


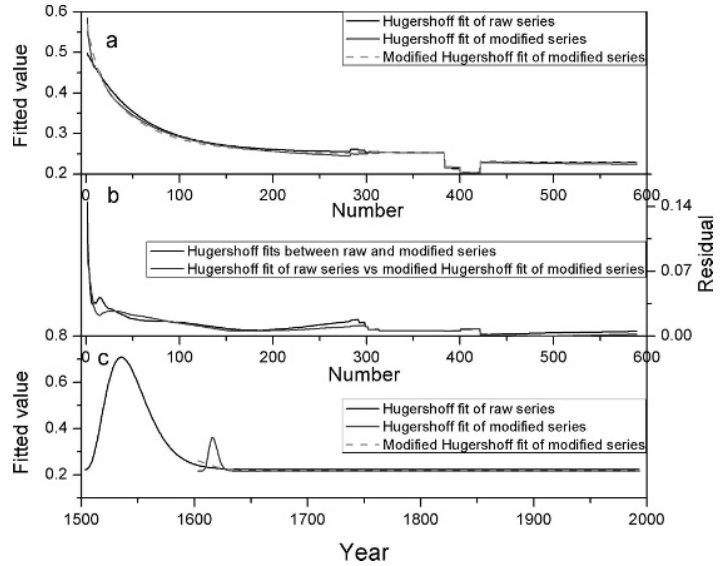

Figure 6. Plot of (a) comparisons of averaged fitted values for a population of raw tree-ring series and those with the first 100 year deleted by using unmodified and modified Hugershoff curves, (b) comparisons of averaged residuals between fitted curves for a population of tree-ring series using differing curves, as well as (c) an example of comparisons of fitted values for one (Dulan44c) out of a population of tree-ring series with differing starting years using different curves.

difference between means of fitted curves using unmodified and modified Hugershoff curves. The modified Hugershoff curve-fit follows better the Hugershoff curve-fit of raw series at number 200300 , while a poorer curve-fit is seen at around number 100. Because biased fitted values higher or lower than the target curve could be averaged out, we also calculated the mean of absolute difference between targeted fitted values and other curve-fits. Clearly improved curve-fits are seen for the use of modified Hugershoff curve when compared to the Hugershoff curve-fits, particularly significant at around 10, 200-300 and since the 450 (Figure 6b). Poorer curve-fits for the use of modified Hugershoff curve are only seen around number 50 (Figure 6b). One example (Dulan44c) that illustrates the better curve-fit of modified curve is shown in Figure 6c, where the fitted peak at the beginning of series is largely reduced by using modified curves.

\section{DISCUSSION}

\section{Modified Hugershoff Curves and Start-Fitting Problem}

Three parameters with biological meanings, the MG, MS and MRS, are calculated from the derivatives of Hugershoff curve. The MG indicates the year when radial growth of trees reaches the maximum growth rate, the MS indicates the year when trees experience the sharpest decline, and the MRS means the year between a decline growth and a flat growth pattern. The disturbances occurring in the innermost tree rings could be over-fitted and bias the Hugershoff curve-fit, which is referred to as the start-fitting problem. Tree rings tend to be better fitted by deterministic curves of similar shapes. Therefore three modified Hugershoff curves are proposed to fit tree rings with differing growth patterns of the innermost tree rings. We suggest visually plotting the tree-ring data before empirically selecting the alternative modified Hugershoff functions. Tests of the use of these modified Hugershoff curves for one series and a population of tree-ring series indicated improved curve-fit. Meanwhile, we stress that the ability of curve-fit of these new function needs more testing, and the aim of this study is to present some new alternatives for the standardization of tree-ring series based on deterministic curves.

\section{End-Fitting Problem and Potential Solutions}

The end-fitting problem for Hugerhsoff curve-fit described herein suggests that the disturbances for a certain period could bias the global fitted Hugershoff curve, which is similar to the end-effect problem stated by Melvin (2004) and the segment length curse (Cook et al. 1995; Melvin and Briffa 2008). We demonstrate that this endfitting problem is an intrinsic problem based on the three parameters of the Hugershoff curve. The calculations of the MG, MS and MRS can be represented by the formula $t=\frac{f(b)}{c}$, where $f(b)$ is equal to $b$ for the MG, to $b \pm \sqrt[c]{b}$ or $b \pm i \sqrt{-b}$ for the MS, and to $b+\sqrt[3]{b}(\sqrt[3]{1+\sqrt{1-b}}+$ $\sqrt[3]{1-\sqrt{1-b}})$ or $b+2 \sqrt{b} \cos \frac{\theta}{3}$ for the MRS. Because the calculations for $f(b)$ are different, these parameters can be the same only on condition that both $b$ and $c$ are exactly the same. If one parameter reaches the same value based on different $b$ and $c$, the other two are hypothetically different. For example, if $b=1, c=0.1$, and $b=$ 0.1 , then $c=0.01$ for two series, MG is the same (10) for both series, while the MS (MRS) values 
are 20 (30) and 42 (75), respectively. Different values of MG, MS and MRS mean different changed shapes of the fitted curves. Because no two tree-ring series could be exactly the same as a result of, for example, changed segment length and/or short disturbances for one series, it is impractical to use the same Hugershoff curve to fit different series. This seems to be an unsolved problem for the fitting process using the deterministic Hugershoff curve. These parameters for different series might be relatively stable if $f(b)$ was less variable. The essential difference for the calculations of $f(b)$ for these parameters is the varying powers of the $b$, i.e. power 1 for the MG, power $1 / 2$ for the MS, and power $1 / 3$ for the MRS. For different values of $b, f(b)$ tend to be less variable when the value of $b$ close to 1 .

Because disturbances occurring in one period can bias the fitted values in other periods, we tried to fit tree-ring series using different deterministic curves for different time spans (detailed results not shown). For example, we separately fitted the treering series of strong variability and flat shape using functions (1) and (7). An observed poor curve-fit might be caused by the difference in shapes between fitting function and the tree-ring series. It may be applicable on the condition that the tree-ring series in separate time periods could be fitted by functions of similar shapes. We have tested this method because it is a relatively flexible curve-fit for treating data in separate time spans with different corresponding functions (Friedman 1984). Because the flexible separate curve-fit would remove more low-frequency signals (Friedman 1984), it is better to have the curve-fit be both deterministic and flexible. The time-span would determine the smoothness and the portion of the retained low-frequency signals of the fitted curve (Friedman 1984). It might be possible to vary the time span to produce both flexible and deterministic curve-fit. For example, it might be practical to compose a deterministic function for fitting separated time-spans with a parameter to determine how much low-frequency signal to retain as introduced by Friedman smoother (1984). This standardization curve with both adaptive and deterministic features needs more exploration.

\section{ACKNOWLEDGEMENTS}

We are grateful to Paul Sheppard for using the tree-ring data that was submitted to the ITRDB. Constructive comments and suggestions from Edward Cook and two anonymous reviewers are highly appreciated. This research was supported by the National Basic Research Program of China (973 Program) (408900501), the NSFC Innovation Team Project (40721061), National Science Foundation of China (No. 40971119), and the Chinese 111 Project (No. B06026). This is Lamont-Doherty Earth Observatory contribution 7306.

\section{REFERENCES CITED}

Bräker, O. U., 1981. Der Alterstrend bei Jahrringdichten und Jahrringbreiten von Nadelhölzern und sein Ausgleich. Mitteilungen der Forstlichen Bundesversuchsanstalt 142: 75-102.

Briffa, K. R., P. D. Jones, T. S. Bartholin, D. Eckstein, F. H. Schweingruber, W. Karlén, P. Zetterberg, and M. Eronen, 1992. Fennoscandian summers from AD 500: temperature changes on short and long timescales. Climate Dynamics 7: 111-119.

Briffa, K. R., P. D. Jones, F. H. Schweingruber, S. G. Shiyatov, and E. R. Cook, 1995. Unusual twentieth-century summer warmth in a 1,000-year temperature record from Siberia. Nature 376:156-159.

Cook, E. R., and K. Peters, 1981. The smoothing spline: A new approach to standardizing forest interior tree-ring width series for dendroclimatic studies. Tree-Ring Bulletin 41:45-53.

Cook, E. R., and L. A. Kairiukstis, 1990. Methods of Dendrochronology: Applications in the Environmental Sciences. Kluwer Academic Publishers, Dordrecht, The Netherlands.

Cook, E. R., K. R. Briffa, D. M. Meko, D. A. Graybill, and G. Funkhouser, 1995. The 'segment length curse' in long treering chronology development for palaeoclimatic studies. The Holocene 5:229-237.

Cook, E. R., and K. Peters, 1997. Calculating unbiased tree-ring indices for the study of climatic and environmental change. The Holocene 7(3):361-370.

Cook, E. R., C. A. Woodhouse, C. M. Eakin, D. M. Meko, and D. W. Stahle, 2004. Long-term aridity changes in the western United States. Science 306:1015-1018.

Esper, J., E. R. Cook, and F. H. Schweingruber, 2002. Lowfrequency signals in long tree-ring chronologies for reconstructing past temperature variability. Science 295:22502253.

Esper, J., E. R. Cook, P. J. Krusic, K. Peters, and F. H. Schweingruber, 2003. Tests of the RCS method for preserving low-frequency variability in long tree-ring chronologies. Tree-Ring Research 59(2):81-98. 
Friedman, J. H., 1984. A variable span scatterplot smoother. In Laboratory for Computational Statistics, Stanford University Technical Report No. 5.

Fritts, H. C., 1976. Tree Ring and Climate. Academic Press, London, UK.

Helama, S., M. Lindholm, M. Timonen, and M. Eronen, 2004. Detection of climate signal in dendrochronological data analysis: A comparison of tree-ring standardization methods. Theoretical and Applied Climatology 79:239-254.

Melvin, T. M., 2004. Historical Growth Rates and Changing Climate Sensitivity of Boreal Conifers. PhD thesis, University of East Anglia, UK.

Melvin, T. M., and K. R. Briffa, 2008. A "signal-free” approach to dendroclimatic standardization. Dendrochronologia 26: $71-86$.
Sheppard, P. R., P. E. Tarasov, L. J. Graumlich, K. U. Heussner, M. Wagner, H. Österle, and L. G. Thompson, 2004. Annual precipitation since $515 \mathrm{BC}$ reconstructed from living and fossil juniper growth of northeastern Qinghai Province, China. Climate Dynamics 23:869-881.

Warren, W. G., 1980. On removing the growth trend from dendrochronological data. Tree-Ring Bulletin 40:35-44.

Warren, W. G., and S. L. MacWilliam, 1981. Test of a new method for removing the growth trend from dendrochronological data. Tree-Ring Bulletin 41:55-66.

Yang, Q. Y., 2002. Advanced Mathematics. Higher Education Press, Beijing, China.

Received 28 October 2008; accepted 27 September 2009. 